\title{
REPRESENTASI KESENJANGAN SOSIAL DALAM FILM PARASITE (ANALISIS SEMIOTIKA ROLAND BARTHES)
}

\author{
Patmawati $^{1}$, Hamdan'2, Masyhadiah ${ }^{3}$ \\ 1Prodi Ilmu Komunikasi, Fakultas Ilmu Sosial dan Ilmu Pemerintahan \\ Universitas Al Asyariah Mandar \\ Email: patmawatifatra0@gmail.com \\ ${ }^{2}$ Prodi Ilmu Komunikasi, Fakultas Ilmu Sosial dan Ilmu Pemerintahan \\ Universitas Al Asyariah Mandar \\ Email: hamdanunasman@gmail.com \\ 3Prodi Ilmu Komunikasi, Fakultas Ilmu Sosial dan Ilmu Pemerintahan \\ Universitas Al Asyariah Mandar \\ Email: masyhadiah22asraruddin@yahoo.com
}

\begin{abstract}
This study aims to identify the social inequality represented in the film Parasite. This research uses Roland Barthes' semiotic analysis method which consists of two stages of marking, namely denotation and connotation. Supporting data in this study uses literature study to obtain relevant theories and data that can be used to solve problems. The results showed that in denotation and connotation there is a meaning of social inequality in the Parasite film which is shown through several markers in the form of audio and visual. Forms of social inequality such as education inequality, inequality in living environment, gap of opportunity. Surrounding myths such as the myth of education fever and the sanpo generation. Meanwhile, the ideology that surrounds it is the ideology of individualism, which is delivered by the capitalist economic system.
\end{abstract}

\section{ABSTRAK}

Penelitian ini bertujuan untuk mengidentifikasi kesenjangan sosial yang direpresentasikan dalam film Parasite. Penelitian ini menggunakan metode analisis semiotika Roland Barthes yang terdiri dari dua tahap penandaan yaitu denotasi dan konotasi. Data pendukung dalam penelitian ini menggunakan studi pustaka guna mendapatkan teori yang relevan serta data-data yang dapat digunakan untuk menyelesaikan masalah. Hasil penelitian menunjukkan bahwa secara denotasi dan konotasi terdapat makna kesenjangan sosial dalam film Parasite yang ditunjukkan melalui beberapa penanda dalam bentuk audio dan visual. Bentuk kesenjangan sosial seperti kesenjangan pendidikan, kesenjangan lingkungan tempat tinggal, kesenjangan kesempatan. Mitos yang 
melingkupi seperti mitos demam pendidikan dan generasi sanpo. Sedangkan ideologi yang melingkupi adalah ideologi individualisme, yang diantar oleh sistem ekonomi kapitalis.

KataKunci: Film Parasite, Kesenjangan Sosial, Representasi, Semiotika, Roland Barthes.

\section{PENDAHULUAN}

Film merupakan media massa dalam kajian ilmu komunikasi, yang dianggap memiliki pengaruh yang pada khalayaknya. Film mengombinasikan gerakan, gambar, musik, dan suara menjadi satu, membuat film mampu melakukan komunikasi dengan cara efektif. Karakteristik inilah yang membuat film menjadi media populer yang digemari oleh semua kalangan. Film adalah kajian media massa yang mengalami perkembangan. Pada awal kemunculannya film hanya dipandang sebagai media hiburan saja dan pelarian dari rutinitas (McQuail, 2012). Namun seiring dengan perkembangan industri, film tidak lagi dipandang hanya sebatas hiburan dan penyampai informasi, tetapi kini memuat ideologi, politik atau bahkan berbentuk kritik sosial dan kontrol sosial terhadap masyarakat.

Media film memiliki ciri-ciri dapat menyebarkan pesan secara serentak, dan memiliki khalayak yang heterogen menjadikan film tergolong sebagai salah satu media massa. Menurut McQuail (2012) film merupakan media massa yang sesungguhnya karena mampu menjangkau populasi dengan jumlah yang besar dan cepat, bahkan di wilayah pedesaan. Film melakukan fungsi media massa sebagai alat penyebaran budaya, mendidik, menginformasikan, dan menghibur (Ardianto, 2007). Oleh sebab itu, film mempunyai kekuatan dan memainkan peranan penting dalam masyarakat, yaitu sebagai katalisator perubahan sosial. Seiring dengan perkembangan zaman dan kemajuan industri film, film menjadi kajian yang menarik. Hal tersebut terbukti dengan banyaknya penelitian terkait film. Menurut Craig, film sebagai bagian dari riset hiburan akan menjadi pokok utama dalam ilmu komunikasi di masa mendatang karena riset tersebut menawarkan kesempatan besar untuk meningkatkan koneksi diantara berbagai disiplin ilmu komunikasi (Berger, dkk, 2015).

Karena film merupakan media penyampaian pesan, maka film dapat digunakan untuk mempengaruhi pikiran penontonnya. Sebagai media, tidak sekedar memproduksi cerita, tetapi juga pikiran dan bahkan memproduksi identitas sosial, merepresentasikan kelas, dan lebih jauh memproduksi ideologi (Hamdan, 2019).

Film merupakan media representasi karena menggambarkan ulang realitas yang ada. Menurut Marcel Danesi (2010), representasi merupakan proses merekam ide dan pengetahuan dalam beberapa cara fisik sehingga 
memiliki fungsi sebagai tanda yang bertujuan untuk melukiskan sesuatu yang dimengerti, dirasa, dan diimajinasikan dalam bentuk fisik. Pekerja film senantiasa berusaha agar film yang diproduksinya dianggap benar-benar merupakan bingkai dari realitas yang terjadi. Mereka akan menyusun sedemikian rupa untuk mengkonstruksi sebuah realitas ke dalam sebuah cerita yang diangkat ke dalam film. Dengan kata lain, film mengandung ideologi pembuatnya yang dapat mempengaruhi pandangan masyarakat terhadap suatu hal. Terdapat kepentingan dalam sebuah penyampaian media, tidak berbeda dengan media film yang merupakan salah satu media massa yang populer. Berdasarkan sifat film yang jangkauannya luas, sifatnya yang riil, dampak emosional dan popularitasnya menjadikan film sangat rentan terhadap gangguan dari luar dan sering kali tunduk pada tekanan untuk seragam karena terlalu banya modal yang terlibat (McQuail, 2012). Film mendapat pengaruh dari referensi kultur pembuatnya, sehingga sangat subjektif dalam merepresentasikan kondisi di sekitarnya.

Film dibuat untuk membungkus makna yang ingin disampaikan, makna tersebut dapat diurai dengan menggunakan analisis semiotika. Menurut Van Zoest (Sobur, 2009) film dibangun dengan tanda-tanda semata. Semiotika adalah suatu ilmu atau metode analisis untuk mengkaji tanda. Sehingga film merupakan kajian yang sangat relevan dengan ilmu semiotika. Tradisi semiotika terdiri atas sekumpulan teori tentang bagaimana tanda-tanda merepresentasikan benda, ide, keadaan, perasaan, dan kondisi di luar tandatanda itu sendiri (Littejohn \& Foss, 2015). Tanda-tanda di sini adalah alat yang digunakan dalam upaya untuk mencari jalan di dunia ini, di tengah-tengah dan bersama-sama manusia. Semiotika atau semiologi dalam istilah Barthes, pada dasarnya hendak mempelajari bagaimana manusia (humanity) memaknai halhal (things) (Sobur, 2009).

Roland Barthes adalah salah seorang tokoh yang memandang penting analisis semiotika dalam film. Barthes merupakan penerus semiotika strukturalis Ferdinand de Saussure. Ia mengembangkan teori semiotika ke dalam dua tahap penandaan (two order of signification), yaitu denotasi dan konotasi (Fiske, 2007). Denotasi merupakan makna yang sebenarnya yang sama dengan makna lugas untuk menyampaikan sesuatu yang bersifat faktual. Sedangkan Konotasi merupakan makna yang bukan sebenarnya atau makna yang mengalami perubahan.

Pada penandaan tahap pertama untuk menentukan makna denotasi, tanda bekerja dengan bahasa (language) sehingga makna yang diperoleh merupakan makna yang umum atau terdapat kesepakatan. Sementara pada proses penandaan yang kedua untuk memperoleh makna konotasi tanda bekerja dengan mitos (myth). 
Secara umum kesenjangan sosial atau social inequality merupakan produk sosial yang berbentuk hierarkis akibat ketidakmerataan distribusi sumber daya dan hak-hak individu. Sumber daya yang didistribusi secara tidak merata bisa dalam bentuk pendapatan atau kekayaan. Isu terhadap masalah di atas yang diangkat ke dalam film yang berjudul Parasite. Sutradara Bong berkata bahwa keluarga merupakan kelompok paling dasar dalam masyarakat. Saya berusaha mengilustrasikan kehidupan dua keluarga ekstrem tanpa menggunakan istilah sosial-ekonomi seperti polarisasi. (Yonhap, 2019). Film Parasite merupakan gambaran terhadap persoalan sosial yang dihadapi Korea Selatan saat ini sekaligus gambaran terhadap masa depan sebuah masyarakat yang semakin kapitalis.

Salah satu film yang menarik untuk dianalisis secara semiotik adalah film Parasite (Gisengchung). Film Parasite merupakan film asal Korea Selatan produksi Baruson E\&A yang disutradarai oleh Bong Joon Ho. Parasite menjadi perbincangan seluruh dunia setelah memenangkan empat Piala Oscar dari enam nominasi pada perhelatan Academy Awards 2020, setelah sebelumnya memenangkan penghargaan paling bergengsi di Festival Film Cannes, Palm de'Ore pada tahun 2019. Film Parasite menjadi film Asia pertama yang menang kategori Best Original Screenplay (Naskah Terbaik). Film non-English pertama yang memenangkan kategori Best Picture (Film Terbaik), dan Sutradara asal Korea Selatan pertama yang memenangkan Best Director (Sutradara Terbaik). Film yang berdurasi 131 menit ini memiliki genre yang unik, tragicomedy, yaitu kisah tragis yang dikemas dengan komedi. Film Parasite merupakan kritik sosial terhadap sistem ekonomi kapitalis Korea Selatan yang melahirkan kesenjangan sosial. Meskipun film tersebut dibalut kental dengan budaya Korea Selatan, tetapi berhasil memikat perhatian dunia berkat kisah yang akrab dengan kehidupan sehari-hari dan relevan dengan situasi di berbagai negara.

Film Parasite dapat disebut sebagai film yang metaforis karena lebih banyak mengemas cerita melalui simbo-simbol daripada narasi secara gamblang. Seperti penggunaan "tangga" untuk menggambarkan high-low (kelas atas dan kelas bawah), "akses matahari" untuk menyatakan bahwa semakin miskin semakin sedikit akses matahari yang didapatkan, dan masih banyak lagi. Selain itu, dalam film tersebut banyak dijumpai penggunaan alegori, misalnya kata "miskin" tidak pernah digunakan, namun direpresesntasikan dengan "bau".

Karena itu, menarik untuk melakukan sebuah studi untuk menganalisa makna kesenjangan sosial yang direpresentasikan dalam film Parasite, dengan menggunakan kerangka analisis semiotika model Roland Barthes untuk mengidentifikasi makna denotasi, konotasi serta mitos dan ideologi di baliknya. 


\section{METODE PENELITIAN}

Penelitian ini menggunakan jenis penelitian kualitatif dengan pendekatan deskriptif, yakni menggambarkan, menganalisis, mencatatat serta menginterpretasi tanda dan simbol yang merepresentasikan kesenjangan sosial dalam film Parasite. Objek penelitian ini adalah film Parasite asal Korea Selatan, garapan sutradara Bong Joon Ho yang berdurasi 131 menit. Teknik analisis data menggunakan analisis semiotika Roland Barthes yang membagi dua tahap penandaan yaitu denotasi dan konotasi. Denotasi sebagai penandaan tahap pertama, kemudian konotasi sebagai penandaan tahap kedua untuk memperoleh mitos dan ideologi yang melingkupi. Data pendukung dalam penelitian ini yaitu penelitian pustaka (library research) yaitu mengkaji dan mempelajari literatur-literatur yang terkait permasalahan dalam penelitian.

\section{HASIL PENELITIAN}

Film Parasite merupakan film yang mengangkat kisah keluarga dengan perbedaan status sosial yang sangat ekstrem. Keluarga Park berasal dari keluarga elit alias konglomerat terdiri dari Park Dong-ik, Park Yeon-kyo, Park Da-hye, dan Park Da-song sementara keluarga Kim adalah keluarga kelas buruh rendahan yang terdiri dari Kim Ki-taek, Kim Chung-sook, Kim Ki-woo, dan Kim Ki-jung. Kedua keluarga merupakan merupakan jenis keluarga inti dengan anggota berupa ayah, ibu, dan dua orang anak. Keluarga Kim merupakan keluarga dari kelas bawah. Pak Kim yang berulang kali gagal dalam berbisnis, Bu Kim yang dahulu seorang atlet tidak pernah benar-benar menemukan kesuksesan, putra putrinya berulang kali gagal ujian masuk universitas. Sementara keluarga Park merupakan orang kaya baru (bukan keturunan orang kaya). Park merupakan CEO perusahan IT, memiliki istri muda dan cantik, putri cantik masih SMA, dan anak putra yang masih muda. Bagi masyarakat kota modern, keluarga Park terlihat seperti keluarga utopis. Interaksi kedua keluarga dari latar belakang kelas sosial berbeda, menjadi topik utama dalam film tersebut. Gambaran masyarakat yang semakin individualis, hubungan antar sesama yang saling menguntungkan sulit ditemukan, keadaan dan kondisi yang memaksa untuk hidup dalam hubungan parasitis.

Setelah dilakukan penelitian menggunakan analisis semiotika model Roland Barthes, peneliti menghimpun 11 gambar dari beberapa adegan yang dianggap merepresentasikan kesenjangan sosial dalam film tersebut. Setelah peneliti memaknai secara Denotasi dan Konotasi, dari 11 gambar tersebut peneliti mengklasifikasi dalam tiga bentuk kesenjangan sosial, yaitu kesenjangan pendidikan, kesenjangan lingkungan tempat tinggal, dan kesenjangna kesempatan. 


\section{Makna Denotasi}

Kesenjangan pendidikan ditampilkan melalui adegan Ki-jung yang tidak lanjut sekolah meskipun berbakat. Ki-woo gagal ujian masuk perguruan tinggi (seunung), meskipun oleh sahabatnya dinilai mampu mengajar bahasa Inggris lebih baik dari pada anak mahasiswa lainnya. Sementara keluarga Park mendapat pendidikan terbaik sejak usia dini. Orang tuanya rela membayar mahal untuk pendidikan anak-anaknya.

Kesenjangan lingkungan tempat tinggal dihadirkan secara visual dalam film tersebut. Keluarga Park adalah masyarakat kelas satu di Korea Selatan. Mereka tinggal di sebuah mansion yang dibangun oleh arsitektur ternama. Mansion bergaya modern, minimalis dan bergengsi berlokasi di bagian tertinggi kota dengan halaman luas nan hijau. Sementara Keluarga Kim tinggal di sebuah semi-basemen (banjiha) di wilayah bagian paling rendah kota, di rumah sempit, lembab, acak-acakan, penuh serangga dan bau.

Kesenjangan kesempatan ditampikan dengan usaha keluarga Kim yang berulang kali gagal, baik dalam upaya mencari pekerjaan, maupun pendidikan. Secara verbal yang terlihat pada dialog antara Pak Kim dan putranya bahwa manusia seperti mereka tidak seharusnya berencana, karena apapun yang mereka rencanakan tidak akan pernah berjalan sesuai dengan keinginannya. Pak Park yang berulangkali menekan kalimat "saya paling tidak senang dengan orang yang melewati batas" dan bau khas keluarga Kim yang oleh keluarga Park dijadikan sebagai lelucon. Secara visual diilustrasikan dengan kehadiran banyak sekali tangga dalam film tersebut dan adegan "air yang mengalir dari atas ke bawah" mengilustrasikan tidak adanya kesempatan mobilitas sosial.

\section{Makna Konotasi (Mitos dan Ideologi)}

Makna denotasi di atas kemudian dijadikan sebagai penanda untuk mendapatkan makna konotasi. Hasil yang diperoleh adalah sebagai berikut:

a. Kesenjangan pendidikan.

Sulitnya masuk universitas bukan hanya persoalan biaya tetapi juga harus berebut dengan ribuan calon mahasiswa lain yang memiliki impian sama. Ki-woo yang mendedikasikan waktunya empat tahun untuk mengikuti ujian masuk universitas atau suneung dalam bahasa korea, membuktikan bahwa ujian masuk universitas bukanlah hal mudah. Di Korea, keberhasilan seorang anak memasuki universitas unggulan merupakan suatu kebanggaan besar bagi keluarga (Seth, 2002). Oleh sebab itu, para orang tua rela mengeluarkan biaya yang tidak sedikit untuk mempersiapkan anaknya menghadapi ujian masuk universitas, bahkan sejak usia balita. Ki-woo yang berasal dari keluarga kelas bawah jelas tidak dapat memenuhi kebutuhan pendidikannya layaknya anak- 
anak lain yang mampu membayar pengajar secara privat. Dari adegan ini terlihat adanya kesenjangan antara yang lahir dari keluarga kaya dan keluarga miskin. Ki-woo yang lahir dari keluarga miskin tidak mampu bersaing bukan karena tidak pintar tetapi ia tidak mampu bersaing dengan anak-anak dari keluarga kaya yang sejak kecil menerima asupan pendidikan yang mahal dan berkualitas.

Pendidikan di Korea Selatan merupakan obesesi nasional (Seth, 2002). Begitu tingginya apresiasi masyarakat Korea Selatan terhadap pendidikan, sehingga semua orang berusaha untuk mendapatkan latar belakang pendidikan tinggi. Bahkan muncul istilah "demam pendidikan" yaitu semangat orang tua untuk memberikan pendidikan terbaik bagi anak-anak mereka dengan harapan anak tersebut dapat memperoleh pendidikan yang tinggi, sukses dalam pekerjaan dan memperoleh status yang baik dalam masyarakat. Menurut Lee (Seth, 2002) "demam pendidikan" tidak hanya mengenai keterlibatan kuat dan minat orang tua dalam pendidikan, tetapi juga terkait kepada suatu sosial kompleks yang mencerminkan cara pandang kolektivisme terhadap pendidikan, sistem penghargaan ekonomi, struktur sistem pendidikan, dan dinamika dalam ujian pendidikan. Isu tersebut telah menjadi wacana selama beberapa dekade terakhir. Ini menandakan bahwa hal tersebut merupakan masalah serius dan nyata terjadi dalam masyarakt Korea Selatan.

Demam Pendidikan merupakan implikasi dari ajaran konfusianime yang telah berakar lama dalam masyarakat Korea Selatan. Ajaran Konfusianisme adalah salah satu dari ribuan ajaran filsafat dari Cina. Ajaran ini memasuki Korea sejak ribuan tahun lalu. Dinasti Joseon (1392) menerima Konfusianisme sebagai ideologi resmi dan diterapkan dalam sistem pendidikan, upacara, dan administrasi sipil. Ajaran ini terus berkembang sesuai dengan zaman. Kultur tersebut kemudian membawa dampak negatif, seperti biaya pendidikan yang semakin mahal, tingginya angka bunuh diri pada kalangan pelajar, dan lainlain. Ironinya adalah bahwa ideologi tersebut mengantarkan negera tersebut seperti sekarang ini, yaitu negara modern, memiliki tingkat perekonomian tinggi, dan memiliki tingkat literasi yang tinggi.

b. Kesenjangan lingkungan tempat tinggal.

Bias pembangunan di kota besar, terutama ibu kota negara memang sering di jumpai, tidak peduli negara maju ataupun berkembang. Korea Selatan sebagai negara dengan perekonomian terbesar keempat Asia pun tidak luput dari kesenjangan pembangunan di kota. Di balik gemerlap bangunan pencakar langit, terdapat lingkungan kumuh dengan rumah-rumah yang tidak layak huni. Kesenjangan lingkungan tempat tinggal diilustrasikan secara visual dalam film Parasite. Kelurga Park tinggal di lingkungan yang bersih, terawat, posisi tinggi, dan elit. Sementara keluarga Kim tinggal di lingkungan kumuh, 
posisi rendah, sempit dan tidak sehat. Pada adegan untuk hunian Keluarga Park pergerakan kamera selalu diarahkan ke atas, sementara keluarga Kim yang menempati semi basemen atau banjiha selalu diarahkan ke bawah. Ini semakin menekankan makna high-low antara keluarga Park dan kelurga Kim.

Semi-basemen atau banjiha dalam bahasa Korea adalah bangunan semi bawah tanah yang dibangun pada saat perang antara Korea Utara dan Korea Selatan. Pemerintah Korea Selatan mewajibkan bangunan baru untuk membuat ruang bawah tanah agar dapat digunakan saat keadaan darurat. Setelah perang mulai reda, Korea Selatan berhasil bangkit dari keterpurukan ekonomi. Banjiha kemudian disewakan dengan harga murah. Pada waktu itu menempati banjiha adalah hal yang ilegal karena tidak layak sebagai sebuah hunian. Tetapi karena permintaan hunian yang meningkat pesat serta krisis properti di tahun 1980-an, membuat kebutuhan papan semakin menipis di kota-kota besar. Pemerintah terpaksa melegalkan ruang bawah tanah untuk ditinggali. Saat ini banjiha tidak hanya dihuni oleh keluarga yang berasal dari kelas bawah, bahkan keluarga kelas menengah memilih menyewa banjiha karena tidak mampu membeli tanah yang harganya semakin hari semakin mahal.

\section{c. Kesenjangan Kesempatan.}

Adegan dalam film tersebut, pak Park menekankan bahwa ia sangat tidak menyukai orang yang melewati batas. Kalimat "melewati batas" yang disebutkan pak Park adalah kalimat yang sangat umum digunakan dalam masyarakat Korea. Makna orang yang melewati batas adalah orang yang berkata, bersikap, dan bertingkah laku tidak seharusnya. Misalnya seorang bawahan tiba-tiba berkata sesuatu kepada atasannya yang bernada menggurui. Contoh lain di Korea Selatan dikenal dua cara berbicara yaitu formal dan informal. Berbicara informal hanya dibolehkan pada orang yang sudah saling mengenal yang lahir di tahun yang sama atau orang yang lebih muda darinya. Ketika berbicara informal kepada orang yang lebih tua meski hanya selisih satu tahun, akan dianggap tidak sopan dan 'melewati batas'.

Dahulu orang yang berpendidikan dan berasal dari keluarga kaya atau disebut yangban mendapatkan segala pelayananan. Orang-orang kecil bahkan tidak berhak memiliki nama. Mereka tidak boleh menolak apapun yang diperintahakan kepada mereka. Jika mereka melewati batas, mereka akan dibunuh begitu saja. Sistem kasta di negara itu merupakan warisan dari nenek moyang mereka. Meski tidak seburuk jaman dahulu, namun sistem itu masih melekat hingga masyarakat modern. Kita dapat melihat sikap pak Park adalah seorang yangban di zaman modern, ia sangat tidak menyukai orang yang bersikap tidak sesuai dengan posisinya. Dari sini kita dapat melihat adanya polarisasi, di mana garis pemisah antar kelas terlihat sangat jelas. 
Bau khas yang berasal dari tubuh keluarga Kim adalah bau banjiha. Meskipun mereka menggunakan pewangi yang berbeda, tetap saja bau itu tidak akan hilang selama mereka menghuni rumah semi bawah tanah itu. Bau itu digambarkan pak Park seperti lobak busuk. Bau yang sering tercium saat menaiki kereta bawah tanah. Bau bukan hanya tentang hidung, tetapi juga kelas sosial. Orang kaya yang tinggal di lingkungan yang bersih, jauh dari bakteri, dan rumah dengan sirkulasi udara yang terbaik jelas memiliki bau tubuh yang berbeda dengan keluarga yang menghuni semi ruang bawah tanah, sirkulasi udara yang tidak memadai, posisi toilet yang lebih tinggi dari lantai rumah, banyak serangga, dan lingkungan yang memang kumuh. Dalam film tersebut bau adalah representasi kemiskinan seolah berkata bahwa bagaimanapun mereka mencoba untuk hidup layaknya orang kaya mereka tetap tidak dapat menghilangkan status miskin mereka. Bau kemiskinan itu terus melekat pada mereka sebagai sebuah identitas.

Adegan hujan deras yang membuat lingkungan kumuh yang ditinggali keluarga Kim terendam banjir. Setiap gambar dalam adegan tersebut terlihat air mengalir dari atas ke bawah. Saat Ki-woo berhenti pada salah satu anak tangga dan memandangi kakinya yang dialiri air, Ki-woo seakan melihat ke dalam dirinya dan menyadari bahwa ia dan keluarganya seperti tidak mampu melawan takdir mereka sebagai orang miskin. Ini memperlihatkan bahwa sekeras apapun mereka berusaha, yang miskin akan tetap miskin. Mereka tidak akan sanggup melawan takdir mereka sebagai orang yang terlahir miskin. Adegan air tersebut memperlihatkan bahwa orang yang miskin tetap akan miskin tidak peduli seberapa keras mereka berusaha. Mereka tidak akan mampu melawan takdir mereka sebagai orang yang miskin.

Adegan lain yang memperlihatkan kesenjangan kesempatan adalah banyaknya usaha yang telah dilakukan oleh pak Kim, namun tidak satupun yang berhasil. Hingga akhirnya membuat pak Kim yang percaya bahwa orang seperti mereka (dari kalangan bawah) tidak seharusnya berencana, karena apapun yang direncanakan tidak pernah berjalan sesuai dengan yang diinginkan.

Di Korea Selatan, ada fenomena yang unik terkait seseorang yang menyerah untuk berencana, terminologi terkait fenomena ini adalah generasi Sanpo. Kata sanpo berarti menyerah dengan tiga hal, yaitu hubungan, pernikahan, dan memiliki keturunan. Menurut Lee (Seth, 2002) fenomena ini terjadi karena anak muda semakin kesulitan memperoleh pekerjaan. Secara finansial mereka tidak bergantung pada siapapun di tengah ekonomi yang melambat dan diikuti tingginya angka pengangguran. Fenomena ini dibuktikan dengan rendahnya tingkat maternitas negara tersebut. Korea Selatan mencatat tingkat maternitas terendah pada tahun 2007, yaitu 1,05 anak per perempuan. Sementara angka yang dibutuhkan agar populasi tetap stabil adalah 2,0. 
Meskipun beberapa dekade terakhir pemerintah Korea Selatan mengeluarkan anggaran milliaran dolar untuk mendorong angka kelahiran, tetapi fenomena ini tetap terjadi.

Masyarakat Korea Selatan yang mengkalisifikasi diri mereka ke dalam dua jenis keluarga, yaitu keluarga kalangan "sendok emas" yang terlahir dari keluarga kaya dan keluarga kalangan "sendok perak" yang terlahir dari keluarga miskin. Kesempatan bagi kalangan sendok perak untuk memanjat kelas sosial (mobilitas sosial) hampir tidak ada karena mendapat bloking di mana-mana. Mereka semakin pesimistik di tengah sistem pendidikan dan pasar kerja yang semakin kompetitif. Dalam sebuah masyarakat ketidakadilan sistemik dan bias dalam mendukung elit.

Barthes menyebutkan bahwa mekanisme kerja mitos dalam suatu ideologi adalah sebagai naturalisasi sejarah. Ketika mitos tersebut menyediakan fungsinya untuk mengungkapkan dan membenarkan nilai-nilai dominan yang terdapat dalam masyarakat, maka disitulah nilai ideologis muncul. Ideologi dibalik kesenjangan sosial yang terjadi di Korea Selatan adalah ideologi individualisme yang membenarkan kapitalisme. Unsur utama dalam kapitalisme ada tiga, yaitu: persaingan (competition), individualisme, dan perolehan keuntungan. Sitem ekonomi kapitalisme memberikan kebebasan yang seluas-luasnya bagi individu-indivu untuk melakukan yang terbaik bagi kepentingan mereka masing-masing (Deliarnov, 2005).

Individualisme merupakan hal yang penting dalam sistem kapitalisme, setiap manusia menilai diri mereka sendiri sebagai individu-individu bukan sebagai bagian dari masyarakat. Mereka menopang diri mereka sendiri di atas kedua kakinya dan harus memenuhi kebutuhan peribadi dari hasil kerja kerasnya. Hal tersebut terlihat dalam film Parasite di mana keluarga Kim menghalalkan segala cara demi pemenuhan kebutuhan. Mulai dari memalsukan ijazah, hingga ke penipuan berantai. Kepedulian antar sesama telah dikesampingkan hanya untuk mengejar kepentingan pribadi.

\section{KESIMPULAN}

Setelah dilakukan penelitian terhadap adegan-adegan dalam film Parasite dengan menggunakan analisis semiotika Roland Barthes yaitu memaknai secara denotasi dan konotasi, maka penulis menyimpulkan bahwa Film Parasite merepresentasikan kesenjangan sosial di Korea Selatan yang dihadirkan dalam audio dan visual melalui adegan-adegan, setting serta dialog. Di dalamnya terdapat kesenjangan sosial, seperti kesenjangan pendidikan, kesenjangan lingkungan tempat tinggal, dan kesenjangan kesempatan. Film Parasite mereprepresentasikan kesenjangan sosial di Korea Selatan sebagai sebuah implikasi dari sistem ekonomi kapitalis yang dianut negara tersebut. Meskipun 
tidak dapat dipungkiri bahwa sistem kapitalisme yang membangkitkan perekonomian negara tersebut dari titik terendah hingga ke negara dengan perekonomian terbesar keempat Asia. Hadirnya film Parasite di tengah-tengah kondisi dunia yang cenderung semakin kapitalis memberikan gambaran bahwa dibalik beragam perkembangan industri yang gemerlap, terdapat kehidupan kelas proletar yang bersembunyi dan kesenjangan yang semakin lebar mengikuti.

\section{SARAN}

Saran penulis untuk perkembangan kajian pada bidang Ilmu Komunikasi, sebaiknya perlu dipertimbangkan untuk memperbanyak kajiankajian analisis teks seperti analisis semiotika, analisis framing, dan analisis wacana karena bidang kajian ini sangat membantu dalam memahami pesanpesan dalam proses komunikasi terutama dengan perkembangan media teknologi informasi dan komunikasi yang semakin pesat. Penulis berharap penelitian ini dapat memberikan pemahamanan dan pengetahuan baru dalam melihat makna yang dikemas dalam sebuah film.

\section{DAFTAR PUSTAKA}

Berger, Charles R., Roloff, Michael E. \& Roskos-Ewolsen, David R. (2015). Handbook Ilmu Komunikasi, Cetakan Ketiga. Diterjemahkan oleh Zakkie M. Irfan. Bandung: Nusa Media.

Danesi, Marcel. (2010). Pengantar Memahami Semiotika Media. Yogyakarta: Jalasutra.

Deliarvov. (2005). Perkembangan Pemikiran Ekonomi. Jakarta: PT. Raja Grafindo Persada.

Eriyanto. (2006). Analisi Wacana. Yogyakarta: LKiS

Fiske, John. (2012). Pengantar Ilmu Komunikasi, Edisi Ketiga. Diterjemahkan oleh Hapsari Dwingtyas. Jakarta: PT. Raja Granfindo Persada.

Hamdan, H. (2019). Wacana dalam Perspektif Norman Fairclough. Jurnal Komodifikasi, Volume 7(1).

Littlejohn W. Stephen \& Foss A. Karen. (2014). Teori Komunikasi (Theories of Human Communication). Diterjemahkan oleh Mohammad Yusuf Hamdan. Jakarta: Salemba Humanika.

McQuail, Denis. (2012). Teori Komunikasi Massa McQuail (McQuail's Mass Communication Theory). Diterjemahkan oleh Putri Iva Izzati. Jakarta: Salemba Humanika. 
Mulyana, Dedy \& Solatun. (2013). Metode Penelitian Komunikasi: ContohContoh Penelitian Kualitatif dengan Pendekatan Praktis. Bandung PT Remaja Rosdakarya.

Seth, Michael J.. (2012). Education Fever: Society Politics, and the Persuit of Schooling in South Korea. Honolulu: University of Hawai Press.

Sobur, Alex. (2009). Analisis Teks Media: Suatu Pengantar untuk Analisis Wacana, Analisis Semiotika dan Analisis Framing, Cetakan Keenam. Bandung: PT. Remaja Rosdakarya.

Yonhap. (2019). Director's Bong Said Something about Parasite . Diakses 20 Februari 2020. https://men.yna.co.kr/view/AEN20200210007500315. 